\title{
Presidential Address*
}

\section{The vision and mission of a roadmap towards our Golden Jubilee in 2046}

\author{
*Shaman Rajindrajith ${ }^{1}$
}

Sri Lanka Journal of Child Health, 2021: 50(4): 575-582

DOI: http://doi.org/10.4038/sljch.v50i4.9841

(Key words: Vision, Mission, Roadmap, Golden Jubilee, 2046)

\section{Introduction}

I stand here in all humility, to accept this singular honour and privilege that has been bestowed upon me as the $25^{\text {th }}$ President of the Sri Lanka College of Paediatricians (SLCP). I am very deeply indebted to the membership of the College for electing me as the President of this august institution for 2021, an establishment with a 25-year-long dazzling track record as a leader in child healthcare in Sri Lanka. For my part, I give you my solemn pledge to uphold the rich traditions of the College at all times.

It is customary for the newly elected President to address the membership on an academic topic that is close to his or her heart. As all of you are aware, I have every possible reason to speak on paediatric gastroenterology, especially on functional gastrointestinal disorders. Yet for all that, in these times of intense change, albeit in a scenario of rapidly changing landscapes, I believe that as the $25^{\text {th }}$ President I should keep my academic research interests in the backburner and have a wide-angled panoramic look at the future of the College.

I believe, that as the President in the Silver Jubilee year, it is that much more important for me to present my thoughts on a roadmap to take us to the dizzy heights of excellence, in a relentless quest of a committed journey towards our Golden Jubilee.

The questions that I am going to concentrate on are:-

- Where are we as a College right now?

- Where should we be in 2046 when we will be celebrating our Golden Jubilee?

\footnotetext{
Professor of Paediatrics, Department of Paediatrics, Faculty of Medicine, University of Colombo, Sri Lanka

*Address given on induction as President, Sri Lanka College of Paediatricians, July 2021

Correspondence: shamanrajindrajith4@gmail.com
}

https://orcid.org/0000-0003-1379-5052

The author declares that there are no conflicts of interest.

Open Access Article published under the Creative Commons Attribution CC-BY@C (i) License
Let us start dreaming about our future and try to shape it the way we want it to unfold in terms of our abilities, resources, and of course, vision. I firmly believe that we can achieve all our dreams and even more when we work with an end in mind, the shining light at the end of the tunnel.

It is of essence to ascertain our status and situation at the end of the initial quarter of a century of existence of our College before we gaze through the looking glass into the future. Where are we in reality at this crucial juncture of the College as of now, in real time? We need to take stock of the following before thinking of making up a roadmap that we need to follow for the next quarter of a century

\section{Our College as a work force}

- Our current membership

Our current membership is 496. Most of them are working as consultant paediatricians in various parts of the country. In addition, there are retired paediatricians and although the number is small, some are employed full-time overseas. There are also a few clinicians who are not paediatricians but have contributed to the field of paediatrics to uplift child healthcare in this country.

- $\quad$ The different Chapters and affiliated arms of the College

In 2019, the Intensive Care Chapter of the SLCP was inaugurated. Although it started with a handful of dedicated intensivists, we are certain that the chapter will grow in strength in the years to come. In addition, the Neonatal Transport Forum, Resuscitation Council, Adolescent Health Forum, Rare Disease Forum, Child Protection Committee and the Childhood Respiratory Disease Study Circle of Sri Lanka are some of the other working teams of the College. Some of them are active and some are not all that conspicuous through their activities.

- $\quad$ The part played by the sub-specialities Sub-specialties in paediatrics were recognized as formal positions around 2004 to 2006. The initial lot included 
neonatology, neurology, nephrology, cardiology and intensive care. Community paediatrics and paediatric pulmonology were new sub-specialities that started to emerge later. It is imperative to note that these sub-specialities have played a major role in reducing the mortality rates of newborns and children in the country. In addition, the sub-specialists, with their specialised knowledge and skills, have also uplifted the care of needy children. These sub-specialities have very significantly contributed to reduce morbidity and improve the quality of life of children in the country.

- The real role of the Ministry of Health Paediatricians as well as the University Paediatricians

Currently, the majority of our members are from the Ministry of Health. However, the numbers of university paediatricians are also growing. Both groups have an amicable relationship and have contributed immensely to uplift both clinical and research scenarios in the country.

\section{Our finances and assets}

- Our liquid cash savings

Our cash flow essentially depends on the contributions of the pharmaceutical industry and the corporate sector to the Annual Congresses. A small contribution also comes from interest from our fixed deposits in banks. Currently we have around 80 million rupees in our bank deposits.

\section{- Our lands and buildings}

We have our plot of land and the office building. This latter accommodation consists of 2 offices for secretaries, council room, editorial room, president's room, and a small auditorium with a seating capacity for 25 .

2. Our influence on decision-making arms of the legislature

- $\quad$ The Line Ministry of Health and Provincial Health Ministries

Most unfortunately, as a College, we do not have a good and optimal working relationship with the Ministry of Health and Provincial Health Ministries. The line of communication is poor leaving us not all that influential and generally lacking recognition as an important organization. We have lost our representations in certain important positions such as the National Medicine Regulatory Authority (NMRA) due to various reasons totally beyond our control. We have lost our influence in many positions as most of our past councils have not intentionally sought out where we should be in the governing bodies, and committees of the Ministry of Health.

- $\quad$ The Family Health Bureau (FHB)

FHB is an important arm of the Ministry of Health that we have to deal with. This is the administrative health authority of the Ministry of Health which is directly responsible for maternal and child health. They have a huge part to play in the care of newborn babies and children, breast feeding, immunization and school health. Yet again, our lines of communications with the FHB, which leave quite a bit to be desired, had been broken at some points in time and direct representation of the College is no more there in many committees run by the FHB. Sadly, all this has led to sub-optimal relationships with the FHB which has led to certain conflicts in perspectives and losing our advisory capacity as a College.

- $\quad$ The Epidemiology Unit of the Ministry of Health

The Epid Unit, as it is called, is an important branch of the Ministry of Health that we at the College have to work with. The Unit runs one of the most influential and administratively powerful committees, the Advisory Committee on Communicable Diseases (ACCD), which is responsible for decision-making on vaccination of children, control of communicable diseases and several other important areas. There had only been representatives from the College nominated by the Council. Unfortunately, the College has not kept abreast of some of the decisions made by the ACCD which are crucial to child health where the College may need to provide advocacy and even intervene.

\section{- $\quad$ The Ministry of Education}

There is no representation of the College in policy making bodies in the Ministry of Education. Although there had been a few attempts to incorporate a College representative into the decision-making body on school health, these attempts so far have not been successful. As the prime organization which is responsible for the child healthcare in the country, we have so far not had the facilities to influence the decisions on developing curricula, 
changing structure of examinations and other crucial issues with regards to the health of school children.

\section{- Other Professional Colleges}

Apart from minimal interactions through an occasional email communication, our relationship with our colleagues in other professional colleges are also not all that great. We do have a joint session with the Sri Lanka College of General Practitioners annually. In addition, we have our annual sport event with the Ceylon College of Physicians.

\section{- $\quad$ The Government}

We had not had direct dealings with the top officials of the Government for a long time. This has very seriously hampered our ability to provide our perceptions as well as advocacy to the government of the country regarding child healthcare.

- WHO/UNICEF and other NGOS

Our relationship with key world bodies have also been declining over the years.

\section{- $\quad$ The society at large}

Our involvement with our biggest stake holders in child healthcare, i.e., families of the country, had been limited to the handful of events initiated by some of our Past Presidents, such as safe childhood and media appearances by our colleagues on an individual basis.

\section{Our Office and staff}

- Secretarial Assistants

We have one Administrative Assistant who helps us to run the office efficiently and another to deal with the financial matters

- Information Technology(IT) resources and personnel

We do not have anyone to support us with expanding electronic information facilities in the College. Our website work is outsourced to a third party.

\section{Our output}

- $\quad$ The website

We have a well-organized website. This website has our major activities and resources listed on a real-time basis. However, it needs to be expanded and maintained on a day-to-day basis, especially with the current problems brought on by the COVID-19 pandemic.
- The Sri Lanka Journal of Child Health (SLJCH); our flagship academic publication

SLJCH is our official flagship academic publication which has a long track record. With recent expansions, it publishes a wide range of articles from both national and international authors quarterly. The journal has a long history and tradition and is wellrecognized by the authors at all levels and also in countries of the sub-continent. The Editors, the Editorial Board, Reviewers and Authors have put their collective shoulders to the wheel to make it a superlative scientific publication brought out quarterly. This is one thing that the College can be very proud of.

- $\quad$ The Newsletter

For a long time, the College did not have a regular newsletter. The first newsletter was released under the editorship of Dr. Prasad Chathurangana. We are planning to release the newsletter quarterly.

- Webinars and other portals of communication

We have a Zoom link that can accommodate 500 people at any given time and we have our dedicated YouTube channel as well.

\section{- $\quad$ Published Guidelines}

In 2005 a set of guidelines were released to manage common childhood problems. After that some isolated guidelines were released. Clinical utilisation of these guidelines has been quite remarkable.

- $\quad$ Research related activities

The College had been promoting research during the last 25 years. We have several research grants that are being provided annually for young researchers to kick-off their research ventures.

- Educational activities

I believe we can be proud of the educational activities of the College. This area is spearheaded by Dr. Srilal de Silva who undoubtedly has catalysed a real paradigm shift in resuscitation of newborns and children. With the support from a group of untiring young and enthusiastic paediatricians, he runs several resuscitation and emergency courses for trainees and young doctors. The programmes are recognized by the Ministry of Health. 
- $\quad$ Other activities

The College had been in the forefront when it comes to helping children during national disasters. The Tsunami of 2004, and the catastrophe of Meethotamulla garbage dump are two of those examples.

At the end of this soul-searching exercise, it is indeed a matter for some regret that I feel we are financially somewhat poor, non-influential in many respects, and even lacking some crucial resources to try and forge ahead, steaming into the unfathomable future. We cannot sustain ourselves in a meaningful way and achieve all that much during the next 25 years unless and until we change our approach drastically from today itself. A course redirection into the right pathway is perhaps the need of the hour.

Up to now, it is true to say that the College has been spending much of its time over the last 25 years in the following key areas

1. Induction of the President

2. Regional In-person Meetings for the past few years before the COVID-19 pandemic

3. Publications through the Journal

4. A few social activities

5. Training Programmes

6. The Annual Scientific Congress

For the last 2 years our activities were mainly on a reactive mode as a response to major health and social problems brought out by the COVID-19 pandemic and other crises of the hour in child healthcare. However, such a short-term vision has its own inherent problem of focusing only on what you see now or tomorrow. However, I firmly believe that we truly need a much bigger plan and a long-term strategy to take the College to its highest pinnacles. I also believe this will generate a sense of excitement and allow us to think big about our future as a responsible academic organization. I am looking forward to setting things on course for a better future in a committed mission, garnished by a wide-angled vision to reach further vistas of unparalleled splendour.

It seems to me that to achieve our goals, the following need to be accomplished:

1. We need to cater to the needs of children of this country, as well as our membership

2. We need to be financially strong

3. We need to have better infrastructure facilities

4. Build better working relationships with governing bodies

5. Network with other colleges and academic organisations; nationally as well as internationally

\section{The mission and vision for the future}

Let us put child healthcare as the priority. Healthy children in future generations will create a new country which is definitely a better one when we are long dead and gone.

\section{Support young paediatricians and facilitate the development of state-of-the-art paediatric hospitals in the country}

There are a lot of young paediatricians in the country. They are being appointed to many remote areas. Most of these are small hospitals with hardly any worthwhile and much-needed facilities. Just after arriving from their overseas training in a hightech unit either in the UK or Australia, they are given the responsibility of developing a paediatric unit in a remote hospital.

With the economic situation in the country, it is extremely difficult to obtain the vital financial support from the government to develop infrastructure in these hospitals. Therefore, the College should be in the forefront of supporting young enthusiastic paediatricians. This can be achieved by developing relationships with industry and other corporate businesses such as banks, garment factories, as well as business tycoons, philanthropists and Non-Governmental Organisations (NGOs). The College needs a longterm plan to tap these organisations and personnel to obtain financial support from each of them to build and renovate or provide basic equipment to these units. By doing so we can fulfil the dreams of the younger generations of paediatricians and ensure their binding loyalty to the College for their entire lifetime.

For this there should be a set of dedicated and energetic permanent staff in the College for fund raising. A devoted assistant treasurer should take the lead role. Each year, at the least, the College should aim to develop 5-10 units across the country, from the North to the South and from the East to the West.

In addition, the College should also look into the possibility of developing a dedicated paediatric hospital for each province. It is a big project that all of us should look up to as a long-term investment. By engaging in shaping the future of paediatrics in our motherland, we can achieve so many things for our future generations and for our country.

1. We can have a nice working environment for our colleagues.

2. We can expand our sub-specialities.

3. We will also be able to attract more of the brightest of juniors to do paediatrics.

4. We can ensure job security for future generations.

5. Optimize care of children in the country. 
6. Create more job opportunities for other categories of health staff as well.

A collaborative project with the Ministry of Health needs to be developed and we should be in the forefront of negotiations with other countries to support this project. By 2040 we should aim to have fully functioning 9 paediatric hospitals in the country, one in each province. They should be equipped with all facilities including High Dependency Units (HDUs), Intensive Care Units (ICUs), surgical units etc., to cater to children, and several sub-specialities, including cardiology, nephrology, neurology, neonatology, pulmonology, gastroenterology and all other sub-specialities that are yet to develop.

We need to negotiate with the Health Ministry and the Post Graduate Institute of Medicine (PGIM) to improve our postgraduate training and expand it to cater to the needs of these hospitals by 2040 . The country needs more subspecialists, as well as generalists like us who have special interest in particular areas of paediatrics. This will create an unprecedented enthusiasm in the paediatric community and the College will also immensely benefit in the process.

\section{Improvement of the College that are needed to cater to such lofty goals.}

By keeping the proposed expansion of the field of paediatrics in our vision and mission for the future, the College should plan to expand to cater to such a massive need as well.

\section{Financial assets}

We need to build at least a 200 million rupee reserve fund to support the activities of the SLCP by 2040 . If each President could contribute 10-15 million worth of fund-raising, apart from the funds for dayto-day running of the SLCP, we can achieve this in 2040. We should raise our benchmark and raise the bar so that it will be an abiding commitment for all future Presidents. When he or she applies for the post of president a plan should be in place. The president should be amply supported by the treasurer and the assistant treasurer who can run the plan. We cannot afford to have anything other than total commitment and 100 per cent dedication. They should be constantly looking into opportunities to improve the finances of the College, right round the clock.

\section{Our land and building}

Parallel to the expansion of the paediatric hospitals, the College should also expand its own infrastructure, physically, metaphorically and even philosophically.

\section{Our infrastructure}

We should have a 3-5 story building in our premises. I very kindly request all of our membership to look into the future. The building should be something like this......

- A nice car park.

- Offices for secretaries and computer assistants.

- A council room for 50 members.

- A hall of fame.

- A lecture hall with modern facilities for 100 people.

- A skills laboratory and training areas.

- A modern library.

- A rooftop area for camaraderie and relaxation.

I firmly believe that we can achieve this splendid dream for the future generations. The College is not for any of us individually. It is for the future of this country. The thinking angle should be wider than what we currently have for the future.

\section{Our staff}

We should plan to expand our staff to cater to these requirements. There should be several secretaries working in different areas.

\section{A separate Administrative Secretary for the President}

The future Presidents will be very busy people. They will be working in the College almost every day apart from their busy clinical and academic schedules. A separate secretary should run the calendar of the President, coordinate meetings and even schedule telephone calls. That will help a smooth run on the day-to-day life of the President.

A secretary for general affairs of the SLCP

This person should run the office, coordinating all College activities with the external world.

Secretary for fund raising and finances

A separate secretary for this purpose would improve our capabilities in fund raising and management of our finances and assets.

\section{Computer Assistant and a Web Designer}

We have to have an in-house computer wizard. The job description would be maintaining all computers and servers of the College, updating the website on a weekly basis, facilitating distant meetings, running our social media campaigns, and creating a paper free College.

\section{Other supportive staff}

We need a maintenance service (at least 2 people) to look after our building, a task which can easily be outsourced. 


\section{Our Output}

The website

It should be world class. We need to update it regularly with new guidelines, patient information, blogs, educational material, and achievement of the College and members. In addition to the website, we should be able to connect with the general public through social media and other communication methods which will be operating in the future. These will be the communication hubs of the future. Let's anticipate and prepare.

\section{Journal}

This is our flagship scientific communication. The journal is currently doing extremely well. However, there is scope to improve, even a little bit more. The journal will be in demand and the number of submissions will be increasing in parallel with the increasing membership and academics of the country. With its growing reputation, I expect a steady rise in international submissions as well. We may even be able to increase the frequency of publishing the journal and perhaps even attract a well-recognized international publisher. I am personally aware that the editors are working very hard to obtain indexing in the PubMed and I am confident that this will be achieved in the near future, embellishing further its scientific reputation. By 2030 we should have an exclusively electronic submission system where authors can upload their submissions and reviewers can review through the system. This will make the life of the members of the editorial board quite easy. In addition to printing and publishing in the website, we should look into ways of disseminating summaries of key articles through the social media.

\section{Newsletter}

We just started the newsletter. It should remain as an electronic communication to our growing membership. In years to come it should also increase in the number of pages and frequency of release. We probably should look to include a small scientific article in there too.

\section{Webinars and other communications}

We also should plan to update our membership regularly on both medical and non-medical topics using webinars. The facilities in the College should improve to include both national and international experts to educate our membership, seniors as well as juniors. In addition, the academic activities such as Clinical Lecture Demonstrations should be projected to the membership and the trainees in even the remotest parts of the country.

\section{Published guidelines}

Development of guidelines for common childhood illnesses is a mandatory process. There should be a well-balanced guideline committee to coordinate these activities. The guidelines should be updated every 5 years at least to include cutting edge knowledge of research into patient care in Sri Lanka. This will definitely raise the standards of clinical care right across the country.

\section{Funding research}

We should have a bigger research fund to support research of both junior and senior colleagues. The fund should have at least 50, or perhaps even 100 million rupees in deposit. There should be at least 4 competitive research grants each worth at least one million, available each year. We need to negotiate with our well-wishers in Sri Lanka as well as abroad to contribute to the research fund. We should run an annual event (music or drama) to raise funds for research.

\section{Educational activities}

Current educational activities need to be expanded. We should look into the possibility of training a substantial number of neonatologists and paediatricians as certified instructors to run updated APLS and NLS programmes at a regional level. The National Education Coordinators in future should organise these activities from the College. In addition, we should officially contribute to educating nurses and midwives through the Ministry of Health and the Family Health Bureau on a regular basis regarding common paediatric conditions. Our community paediatricians who will be a growing group, and neonatologists, should spearhead these programmes. Through educational activities we will be able to grow and cultivate the influence of the College in every aspect of paediatric care including those at the grassroots and on-field levels.

We should also run a regular summer school for our juniors. College should negotiate with the industry to develop separate, unrestricted grants to develop a fund to support this activity uninterrupted. The topic for each year should be developed by a group of experts in an educational subcommittee of the College. It will at least be a two-day residential programme in a nice user-friendly location for selected 50 junior colleagues who are in training. World renowned experts in the field should be coopted to participate in these sessions. Perhaps we will be able to negotiate with other paediatric societies and colleges across the world to support this activity.

\section{Our influence and professional relationships}

The SLCP should remain as the apex body of child advocacy. We should be able influence every decision with regard to child health in this country and make sure that our voice matters and more importantly, that it is heard. Let us be decision makers rather than following the orders of others. 
We need to carefully plan and improve our influence in decision making bodies of the country. Our relationship with the Ministry of Health should undoubtedly grow into a new dimension. Regular quarterly meetings with the Health Secretary and the Director General of Health Services should be a part of this new relationship. This will enable us to discuss a wide range of issues faced by our membership with the highest authorities and find solutions. In addition, we should work collaboratively with the FHB to ensure that our colleagues in the field of neonatology and community paediatrics get a fair deal. We also should request for representation in all technical committees involved in procuring paediatric and neonatal equipment. Improving relationship with the Epidemiology Unit will allow us to keep track of and exert our influence on communicable diseases affecting children, as well as providing expert input on prevention strategies and immunisation of children.

A new professional relationship should be built with the WHO and UNICEF, both of which are the apex bodies of child healthcare in the world. Quarterly meetings with representatives of these organizations will help us to explore opportunities for collaboration and funding our activities. In future we should work with these organizations to obtain funding to develop and update our guidelines. It would be wonderful to have College Guidelines endorsed by the WHO and UNICEF. We also can request expert input from the world authorities through these organizations. I believe these can only be achieved by having greater and abiding relationships with the country representatives and local staff.

Ministry of Education is another important office that the College should look forward to working with. The College needs to get involved in decision making in educational material, school health and the future of education of children in this country. Through the ministry and the zonal education offices we should have links to deliver correct health messages to the doorsteps of schools. With the right influence, we will be able to contribute to uplift the health of children in the country through developing correct health habits. We, as a responsible body, should constantly try to influence decision makers to enhance both physical and mental health of children.

Our relationship with other professional colleges and organizations should also be developed in the future to achieve the best possible care for our children in 2046. At a local level, we should be closely working with the Ceylon College of Physicians and looking forward to increasing the paediatric cut-off age to 16 years and then to 18 years, the international cut-off age for children, by
2046. With the development of new hospitals, we should develop Adolescent Units where adolescents can have privacy and facilities that meet their needs. Transition of care from paediatrics to adult life is also a neglected area. We should be running transitional care clinics in our hospitals with adult colleagues to smoothen the transition from paediatric to adult care in this vulnerable group. We should also possibly invite our colleagues in the field of paediatric surgery to join the College of Paediatricians as members. We should think of amending our constitution to include a paediatric surgeon into our sub-speciality representation. In addition, we should also improve our relationship with the Royal College of Paediatrics and Child Health of the UK, to obtain more training opportunities for our younger members. We should aim to build new relationships with our fellow paediatricians in US, Europe, Asia, and Australia through their professional colleges and associations to support both our training and academic activities.

\section{How to reach out to the public and the society in general?}

We should aim to reach each household with children to inculcate healthy habits into their life in the era of growing non-communicable diseases. By 2046 , both the burden of morbidity and mortality will be skyrocketing unless we see the threat now and try to influence their lifestyles through coordinated educational activity. Using the expertise that we have in the College, we should be able to achieve this target. We aim to reach every household through social media, television and radio networks. With the right relationships, we can obtain educational time in these networks to communicate with mothers in the country. The College website should also have a section for public education. With our Information Technology (IT) experts we should plan to join reputable networks to reach every possible mobile phone in the country to disseminate flash text messages to improve child health, improve the safety of children and many other endeavours.

Building a research culture among our colleagues I firmly believe that the future belongs to the researchers who tirelessly strive to find the truth. Lack of research initiatives will be a major hindrance to achieve our targets in 2046. We should aim to have a broad research portfolio for Sri Lankan paediatricians by 2046. At least 2500 original articles contributed by our members from 20212046 will not be an unachievable target. We should build a framework to eliminate the currently prevalent inertia for research among our members and juniors. We will be running a series of workshops and will have a team of reputed researchers with proven track records to support research each year. Although it looks like an uphill task to achieve, as an experienced researcher, I am 
sure this is an achievable target. This will make a mark in the global research arena as well.

Ladies and gentlemen,

The path of this proposed roadmap may not be easy to achieve with visions of such a superior set of goals for our beloved College. However, we have nothing to lose. We have worked tirelessly, up to our $25^{\text {th }}$ anniversary, building our foundation as a respected professional body. Now is the time to steadily accelerate our pace to the Golden Jubilee in a focused manner. I am intensely convinced that we can achieve our targets. I am equally sure that this Presidential Address will be a window of opportunity to change the path that we have travelled so far, to a superhighway that would eventually lead us to our Golden Jubilee in 2046.

My dear friends,

I have attempted to present to you just some thoughts and ideas of mine. It was Victor Hugo, that renowned French poet, novelist and dramatist who once said "There is nothing more powerful than an idea whose time has come". The American Philosopher Ralph Waldo Emerson envisioned "The mind, once stretched by a new idea, never returns to its original dimensions" I have stretched your mind by showing the brighter future we can achieve when we follow the path that I have shown.

I believe that the time has indeed come for these ideas of mine to be put into practice. All that we would need is your dedication and commitment to induce these ideas to bear fruit in the future. Thank you for your patient listening and undivided attention.

\section{Acknowledgements}

The author acknowledges the support of Dr. B.J.C. Perera and Dr. G.N. Lucas for their kind assistance in editing the script. 